\title{
Factors associated with malaria infection in Mudzi District, Mashonaland East Zimbabwe, 2019: a case-control study
}

\author{
T. T. Masango ${ }^{1}$, T. K. Nyadzayo ${ }^{2}$, N. T. Gombe ${ }^{1}$, T. P. Juru ${ }^{1 *}$ (D) G. Shambira ${ }^{1}$, S. Chiwanda ${ }^{1}$ and M. T. Tshimanga ${ }^{1}$
}

\begin{abstract}
Background: Kondo Rural Health Centre recorded 27 malaria patients between the 27th of January 2019 and the 2nd of February 2019 against an epidemic threshold of 19 with the malaria outbreak being confirmed on the 5th of February 2019. Indoor residual spraying as part of integrated vector management control activities had been done in the district before the onset of the rainy season as well as social behaviour change communication but residents were contracting malaria. We, therefore, investigated the risk factors associated with this outbreak to recommend scientifically effective prevention and control measures.

Methods: We conducted a 1:1 unmatched case-control study. A case was a resident of Mudzi from the 4th of February 2019 who had a positive rapid diagnostic test for malaria randomly selected from the clinic's line list whilst controls were randomly selected from the neighbourhood of cases. Pretested interviewer-administered questionnaires were used to collect information on demographic characteristics, knowledge and practices of residents in malaria prevention. Data were analysed using Epi info 7.
\end{abstract}

Results: A total of 567 confirmed malaria cases was recorded with an overall attack rate of 71.7 per 1000 population. Sixtythree case-control pairs were interviewed. The majority of cases 78\% (49/63) were from Makaza, Chanetsa and Nyarongo villages which are within $3 \mathrm{~km}$ from Vhombodzi dam. A stagnant water body near a house $[a \mathrm{OR}=8.0,95 \% \mathrm{Cl}=(2.3-28.6)]$, engaging in outdoor activities before dawn or after dusk $[\mathrm{aOR}=8.3,95 \% \mathrm{Cl}=(1.1-62.7)]$ and having a house with open eaves $[\mathrm{aOR}=5.4,95 \% \mathrm{Cl}=(1.2-23.3)]$ were independent risk factors associated with contracting malaria. Wearing long-sleeved clothes when outdoors at night $[\mathrm{aOR}=0.2,95 \% \mathrm{Cl}=(0.1-0.4)]$ was protective.

Conclusion: A stagnant water pool close to the homestead and engaging in outdoor activities before dawn and after dusk were modifiable risk factors associated with the malaria outbreak despite the community being knowledgeable on the transmission and prevention of malaria. Community sensitisation and mobilisation in the destruction of stagnant water bodies and cutting of tall grass around homesteads were recommended measures to contain the outbreak.

Keywords: Malaria, Outbreak, Case-control, Mudzi

\footnotetext{
* Correspondence: tsitsijuru@gmail.com

'Department of Community Medicine, University of Zimbabwe, Harare, Zimbabwe

Full list of author information is available at the end of the article
}

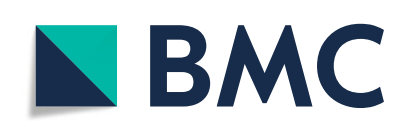

(- The Author(s). 2020 Open Access This article is licensed under a Creative Commons Attribution 4.0 International License, which permits use, sharing, adaptation, distribution and reproduction in any medium or format, as long as you give appropriate credit to the original author(s) and the source, provide a link to the Creative Commons licence, and indicate if changes were made. The images or other third party material in this article are included in the article's Creative Commons licence, unless indicated otherwise in a credit line to the material. If material is not included in the article's Creative Commons licence and your intended use is not permitted by statutory regulation or exceeds the permitted use, you will need to obtain permission directly from the copyright holder. To view a copy of this licence, visit http://creativecommons.org/licenses/by/4.0/. The Creative Commons Public Domain Dedication waiver (http://creativecommons.org/publicdomain/zero/1.0/) applies to the data made available in this article, unless otherwise stated in a credit line to the data. 


\section{Background}

Malaria is the 4th leading cause of preventable morbidity and mortality in Africa, caused by the protozoan parasite Plasmodium species namely P.falciparum, P.malariae, P.ovale, P.vivax and P.knowlesi [1]. It is spread by the bite of an infective female Anopheles mosquito which bites mainly between dusk and dawn [2]. The disease can cause fever, chills, and flu-like illness and if not treated early, it can cause severe complications and death [3]. Young children under 5 years of age and pregnant women are at high risk of infection with malaria [4].

In 2017, two hundred and nineteen million cases of malaria occurred worldwide and 435,000 deaths were reported, mostly children in the African Region [5]. The World Health Organisation's African Region (WHO/ AFRO) had a high contribution to this global malaria burden having contributed $92 \%$ of cases and $93 \%$ of deaths [6]. Global efforts and investments to fight and contain malaria have led to a remarkable reduction in morbidity and mortality in the last decade with the successful elimination of malaria in eight WHO member countries [5]. Malaria surveillance in endemic regions assists in reducing the burden of morbidity and mortality by providing data for trend analysis, resource allocation, vector control monitoring, drug efficacy and resistance and epidemic detection, preparedness and response [7]. Poor epidemic preparedness and response (EPR) can result in the inability to analyse and interpret surveillance data which leads to late notification and delayed outbreak investigation [8].

Zimbabwe has seasonal and geographic variation in malaria transmission that corresponds closely with the country's rainfall pattern. In general, the major malaria transmission season occurs during the rainy season between November and April, with the average temperature ranging between 18 and 30 degrees Celsius [9]. Plasmodium falciparum has been the predominant malaria parasite causing $98 \%$ of all reported malaria cases [10].

Mudzi District in Mashonaland East Province is malaria endemic with some areas traditionally known to be malaria burdened whilst others are almost malaria-free. A review of the weekly disease surveillance data showed that the number of malaria cases with a positive rapid diagnostic test (RDT) at Kondo Rural Health Centre had been on the increase from the 27th of January 2019 with the number of cases almost double the action threshold between the 10th and the 16th of February 2019. There are five villages around Kondo Rural Health Centre with three village health workers assisting in the delivery and promotion of health services. Indoor residual spraying as part of integrated vector management control activities had been done in the district before the onset of the rainy season as well as social behaviour change communication however residents were contracting malaria. This prompted the District Medical Officer to request the Zimbabwe Field Epidemiology Training Program to investigate the malaria outbreak to recommend scientifically effective prevention and control measures. Understanding and documenting the reasons for malaria outbreaks in areas where integrated vector control activities have been done is necessary for the global fight to eliminate morbidity and mortality from malaria. We, therefore, conducted a case-control study to determine the risk factors associated with contracting malaria in this outbreak.

\section{Methods}

Study setting

Mudzi District in Mashonaland East Province of Zimbabwe has an estimated population of 1,366,522 people according to the 2017 intercensal demographic survey with $88.8 \%$ of the population being rural [11]. Agriculture and mining are the main economic activities with $44 \%$ of persons aged 15 years and above economically active. The district has a seasonal burden of malaria with most of the transmission during the wet season and peaking between February and April.

\section{Descriptive epidemiology}

Following an invitation from the District Medical Officer to assist in the outbreak, the District Health Executive was interviewed as the key informants to obtain an overview of the outbreak. Surveillance data, line lists and health records were then reviewed to confirm the outbreak. Active case search and environmental assessments were conducted in the five villages around Kondo Rural Health Centre. Using the generated data, an epidemic curve was constructed and the outbreak characterised by time, place and person.

\section{Study design}

Following the descriptive analysis, it was hypothesised that living close to tall uncut grass or open water bodies was a risk factor associated with contracting malaria. A 1:1 unmatched case-control study was then conducted to test this hypothesis. A case was defined as any person residing in Mudzi District for more than 2 weeks from the 4th of February 2019 and who presented with the onset of any of the following signs and symptoms; fever, headache, muscles and joint pains, chills, body weakness and had a positive rapid diagnostic test (RDT) for malaria. A control was defined as any person living in Mudzi District during the same period that did not develop any of the symptoms of malaria. 


\section{Inclusion criteria \\ Cases}

Any resident of Mudzi District during the outbreak period, with a positive RDT who consented to participate in the study.

\section{Controls}

Any resident of Mudzi District during the outbreak period, who consented to participate in the study and had a negative RDT diagnosis of malaria.

\section{Exclusion criteria}

Individuals who had symptoms suggestive of malaria without RDT confirmation of diagnosis were excluded from the study. Any child below 16 years of age were parental or guardian consent for participation was not readily available or denied.

\section{Sample size}

Using Stat Calc function of Epi Info ${ }^{\mathrm{mm}} 7$, assuming staying within $3 \mathrm{~km}$ from a river, swamp, dam or stream a significant risk factor for contracting malaria with an odds ratio of 2.7 , with $43 \%$ of controls having been exposed (study by Kureya et al.: Malaria Outbreak Investigation in Chipinge, Zimbabwe: A Case-Control Study) using a power of $80 \%$ and confidence interval of $95 \%$ - The calculated minimum sample size was 74 cases and 74 controls.

\section{Sampling}

A line list of malaria cases at Kondo Rural Health Centre was obtained and using numbers assigned to each case, we selected 74 cases using excel generated random numbers. Village health workers were utilised to locate the cases from the respective villages of residence. Controls were randomly selected from the neighbourhood of cases provided they had no clinical diagnosis of malaria.

\section{Data collection}

A pre-tested interviewer-administered questionnaire (supplementary material 1) was used to collect information on demographic characteristics, knowledge and practices of residents in malaria prevention. Most of the questions were adapted from literature and modified to relate to the study's objectives. Knowledge about malaria was assessed by asking study participants about signs and symptoms of malaria and methods of malaria prevention. Knowledge was then rated using a 5-point Likert scale. Checklists (adopted from updated IDSR guidelines) were used to gather information on the availability of resources to contain the outbreak. Medical records were reviewed to ascertain case management.

\section{Data analysis}

Data were captured and analysed using Epi info $7^{\mathrm{rm}}$. Data were manually checked for completeness, duplication and omission before analysis. After validation of entered data, frequencies, means and proportions were generated. Bivariate analysis was then carried out with calculation of odds ratios, their confidence intervals and $p$ values to identify risk and protective factors that were associated with contracting malaria. Stratified analysis was done to check for confounding and effect modification. Stepwise forward logistic regression was done for all variables that were significantly associated with contracting malaria at the $p \leq 0.25$ level on bivariate analysis to determine the independent factors associated with contracting malaria.

\section{Environmental assessment}

A walk-through assessment of housing infrastructure, areas surrounding homes and places where cases and controls spend the majority of their time was done to identify mosquito breeding sites within the community. CDC light trapping and larval dipping were used to collect mosquito and larvae samples which were sent to the laboratory for larvae rearing and adult mosquito identification. Observations were done to see if houses had open eaves and if there was tall uncut grass around the homesteads and stagnant water pools within $200 \mathrm{~m}$ from the homestead. Assessments were also done for the availability of mosquito nets, the utilisation of repellents and confirmation of indoor residual spraying of homesteads before the onset of the rainy season.

\section{Permission and ethical considerations}

Written informed consent was obtained from participants before interviews which were done privately. Written parental or guardian consent was obtained on behalf of all participants under 16 years of age as well as the child's verbal assent to participate in the study. Confidentiality was maintained throughout the study by not recording participant names on questionnaires.

\section{Results}

A total of 567 RDT confirmed malaria case-patients were recorded over the outbreak from week 5 to week 17 of 2019 in the five villages around Kondo Rural Health Centre. The overall attack rate was 71.7 cases per 1000 population (Table 1). Among the malaria cases, $14 \%(79 / 567)$ were from Chanetsa village, 30\% (170/567) were from Makaza village, $10 \%$ (57/567) were from Vhombodzi village, 13\% (74/567) were from Zondo village and 33\% (187/567) from Nyarongo village. The greatest number of cases were recorded in week 11 of 2019 and the epidemic curve demonstrated a propagated outbreak (Fig. 1). 
Table 1 Malaria attack rate by village in Mudzi district, Zimbabwe, 2019

\begin{tabular}{llll}
\hline Village & Population & Number of Cases & Attack Rate/1000 population \\
\hline Chanetsa & 1359 & 79 & 58.1 \\
Makaza & 1945 & 170 & 87.4 \\
Vhombodzi & 1220 & 57 & 46.7 \\
Zondo & 1129 & 74 & 65.5 \\
Nyarongo & 2250 & 187 & 83.1 \\
Total & $\mathbf{7 9 0 3}$ & $\mathbf{5 6 7}$ & $\mathbf{7 1 . 7}$ \\
\hline
\end{tabular}

\section{Characteristics of study participants}

Sixty-three case-control pairs out of a target of 74 were recruited giving an $85 \%$ response rate. The majority of the cases were male at $60 \%(38 / 63)$ compared to $51 \%$ $(32 / 63)$ females in the controls. Sixty percent of cases $(38 / 63)$ were not employed compared to $68 \%$ (43/63) for controls. The highest level of education attained was primary school attendance by both cases and controls at $59 \%(37 / 63)$ and 55\% (35/63) respectively. The median age for cases was 35 years and 31 years for controls. There were no statistically significant differences among cases and controls on the variables: sex, employment status, level of education, religion, age and marital status. Therefore, the socio-demographic characteristics of cases and controls were comparable (Table 2).

\section{Participants knowledge of malaria}

Twenty-two percent (14/63) of cases incorrectly stated infected fruits as the cause of malaria compared to $13 \%$ $(8 / 63)$ of controls. Sixty percent $(38 / 63)$ of cases managed to recall at least 3 signs and symptoms of malaria compared to $67 \%(42 / 63)$ of controls. The most stated symptom among the cases and controls was fever at $83 \%(52 / 63)$ and $79 \%(50 / 63)$ respectively. The most stated malaria prevention method was sleeping under a treated net 67\% (42/63) among cases and 70\% (44/63) among controls. Both cases and controls had a fair knowledge of malaria.

\section{Clinical management of malaria cases}

The most common symptoms amongst the malaria cases were fever $87 \%$ (55/63), body weakness 78\% (49/63), shivering/chills $67 \%(42 / 63)$ and vomiting 56\% (35/63). The majority of the cases were diagnosed by health workers at the clinic $71 \%(45 / 63)$ whilst the remainder $29 \%(18 / 63)$ were diagnosed and treated by their respective village health workers. Malaria confirmation in all cases was done using malaria rapid diagnostic tests and any case confirmed positive was put on a 6 dose course

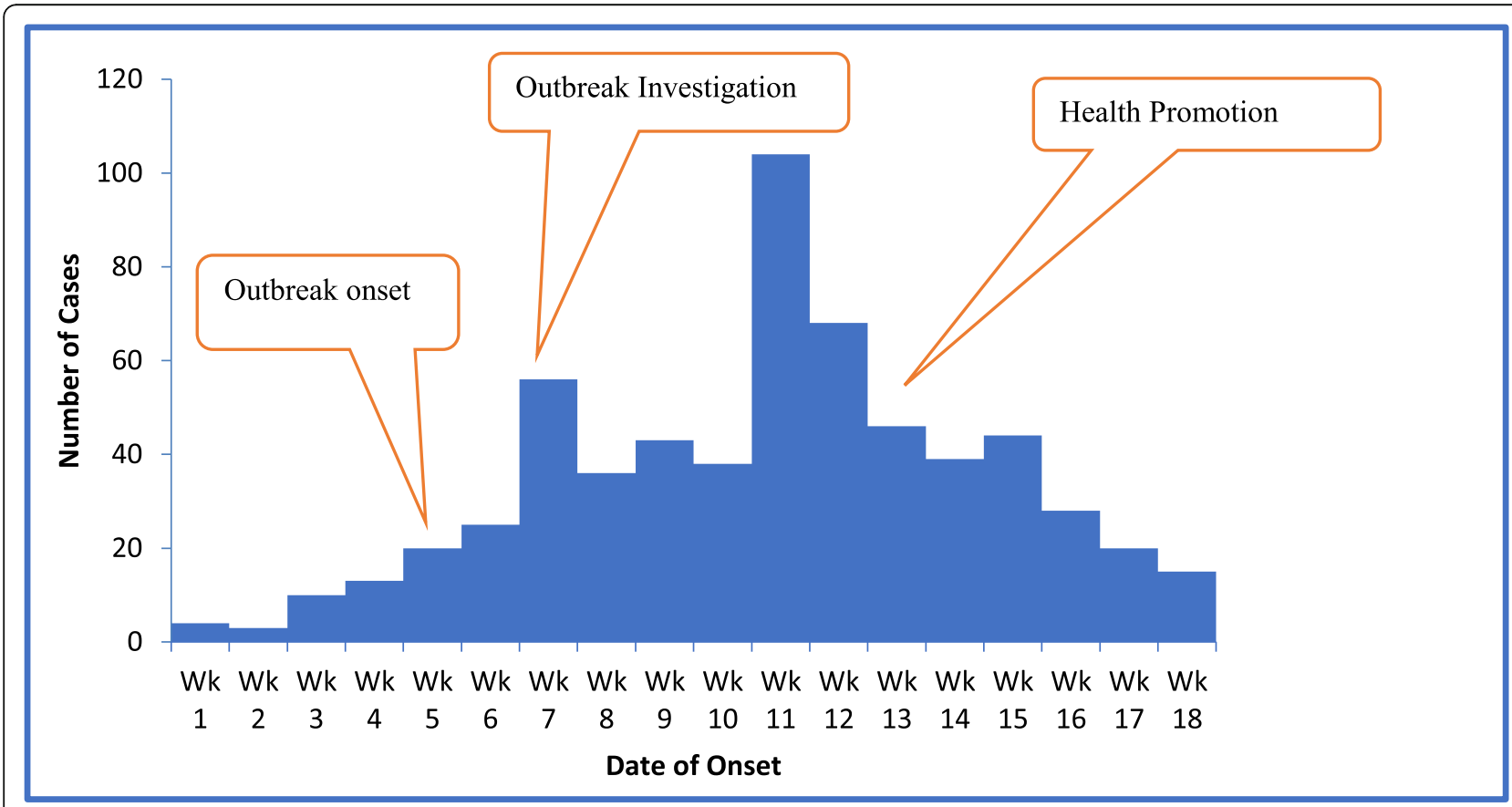

Fig. 1 Epidemic curve of malaria outbreak in Mudzi district, Zimbabwe 2019 
Table 2 Socio demographic characteristics of respondents in Mudzi district, Zimbabwe 2019

\begin{tabular}{|c|c|c|c|c|}
\hline Variable & Category & Cases $n=63(\%)$ & Controls $n=63(\%)$ & $P$ Value \\
\hline \multirow[t]{2}{*}{ Sex } & Male & $38(60)$ & $31(49)$ & 0.28 \\
\hline & Female & $25(40)$ & $32(51)$ & \\
\hline \multirow[t]{2}{*}{ Employment Status } & Casual labourer & $17(27)$ & $13(21)$ & 0.46 \\
\hline & Unemployed & $46(73)$ & $50(79)$ & \\
\hline \multirow[t]{2}{*}{ Marital Status } & Single/Minor & $13(21)$ & $12(19)$ & 0.22 \\
\hline & Married & $50(79)$ & $51(81)$ & \\
\hline \multirow[t]{3}{*}{ Highest level of Education } & None & $11(17)$ & $8(13)$ & 0.54 \\
\hline & Primary & $37(59)$ & $35(55)$ & \\
\hline & Secondary & $15(24)$ & $20(32)$ & \\
\hline \multirow[t]{2}{*}{ Religion } & Apostolic & $43(68)$ & $36(57)$ & 0.41 \\
\hline & Other & $20(32)$ & $27(43)$ & \\
\hline \multirow[t]{3}{*}{ Age } & $<5$ years & $2(3)$ & $3(5)$ & 0.61 \\
\hline & $5-40$ years & $52(83)$ & $48(76)$ & \\
\hline & $>40$ years & $9(14)$ & $12(19)$ & \\
\hline
\end{tabular}

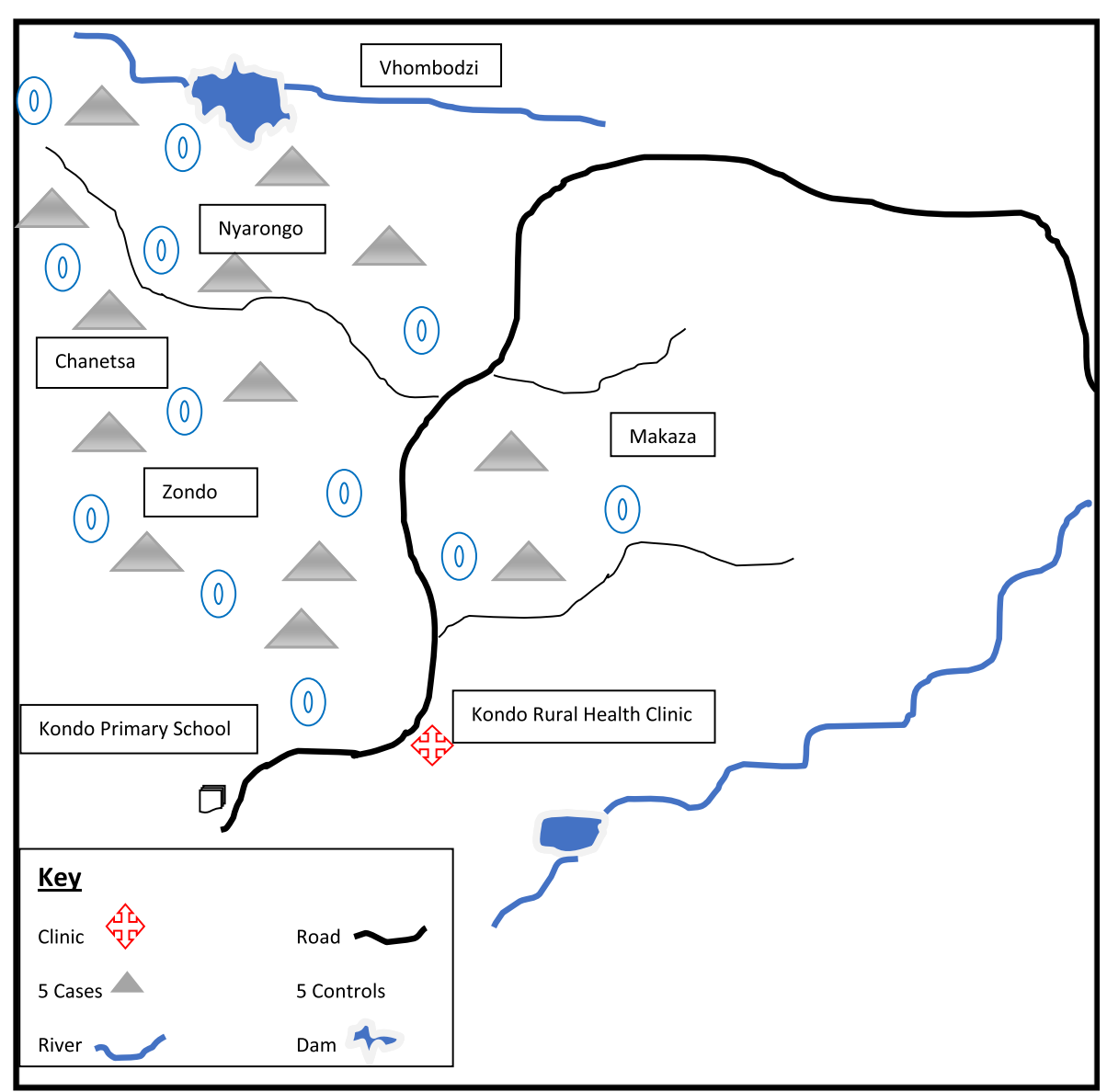

Fig. 2 Distribution of malaria cases and controls in Mudzi district, Zimbabwe, 2019 
of artemether-lumefantrine $(1.5 \mathrm{mg} / 12 \mathrm{mg} / \mathrm{kg})$ according to national treatment guidelines [12].

\section{Environmental assessment}

The majority of the villages $60 \%$ (3/5) serviced by Kondo Rural Health Centre were located within $3 \mathrm{~km}$ from Chanetsa Dam. There are two dams one closer to Kondo Rural Health Centre clinic and another one on the boundary between Nyarongo and Vhombodzi. Small streams and swamps were common features within the villages with most homesteads within $200 \mathrm{~m}$ from these open water bodies (Fig. 2). There were tall uncut grass and stagnant water pools around most homesteads presenting mosquito breeding sites. Anopheles gambiensi and Anopheles arabiensis presence were identified from the sampled mosquitos and larvae. Thirty-nine percent (49/126) of visited homesteads reported not having undergone IRS as either the spraying team did not visit the homesteads as they are far away from the road or they came when no one was around at home. This was also confirmed by the respective village health workers. Seventy-five percent of visited homesteads had houses with open eaves exposing residents to mosquito bites.

\section{Evaluation of the malaria outbreak emergency, preparedness and response}

The clinic staff managed to notify the district health executive (DHE) within $24 \mathrm{~h}$ of the upsurge in malaria cases and the outbreak was declared within 5 days. The emergency preparedness and response team (EPR) managed to mobilize adequate medications (coartemether tablets) for the clinic but had a limited supply of rapid diagnostic kits which were only dispatched to the clinic and none were distributed to the village health workers.

\section{Factors associated with contracting malaria}

In the bivariate analysis, statistically significant risk factors for contracting malaria were living in a house with open eaves $[\mathrm{OR}=8.7,95 \% \mathrm{CI}=(3.1-24.6)]$, having stagnant water bodies within $200 \mathrm{~m}$ from a homestead [OR = $7.5,95 \% \mathrm{CI}=(3.2-17.8)]$, engaging in outdoor activities before dawn and after dusk $[\mathrm{OR}=6.3,95 \% \mathrm{CI}=(2.6-$ $15.2)]$ and having evening meals outdoors at night [OR = 4.5, $95 \% \mathrm{CI}=(2.1-9.9)]$. Living in a house that was sprayed (IRS) $[\mathrm{OR}=0.3,95 \% \mathrm{CI}=(0.2-0.7)]$, wearing long-sleeved clothes when outdoors at night $[\mathrm{OR}=0.3$, $95 \% \mathrm{CI}=(0.2-0.7)]$ and having ever received health education on malaria $[\mathrm{OR}=0.2,95 \% \mathrm{CI}=(0.1-0.6)]$ were significant protective factors against contracting malaria (Table 3).

The association between engaging in outdoor activities before dawn and after dusk and contracting malaria infection stratified by sex were analysed. The crude odds ratio for engaging in outdoor activities before dawn and after dusk lies in between the stratum specific odds ratios. Therefore, the association between contracting malaria and engaging in outdoor activities before dawn and after dusk was modified by sex (male or female). Males who engaged in outdoor activities before dawn and after dusk were 7.3 times $[\mathrm{OR}=7.3,95 \% \mathrm{CI}=(1.8-29.5)]$ likely to contract malaria compared to 5.4 times [OR = 5.4, 95\% CI $=(1.7-17.6)]$ among females who also engaged in outdoor activities before dawn and after dusk (Table 4).

Table 3 Factors associated with malaria infection in Mudzi district, Zimbabwe, 2019

\begin{tabular}{|c|c|c|c|c|c|}
\hline Variable & Exposure Status & Cases $n=63(\%)$ & Controls $n=63(\%)$ & cOR $(95 \% \mathrm{Cl})$ & aOR $(95 \% \mathrm{Cl})$ \\
\hline \multirow[t]{2}{*}{ House with open eaves } & Yes & $58(92)$ & $36(57)$ & $8.7(3.1-24.6) *$ & $5.4(1.2-23.3) * *$ \\
\hline & No & $5(8)$ & $27(43)$ & & \\
\hline \multirow[t]{2}{*}{ Stagnant water body near house } & Yes & $54(86)$ & $28(44)$ & $7.5(3.2-17.8) *$ & $8.0(2.3-28.6) * *$ \\
\hline & No & $9(14)$ & $35(56)$ & & \\
\hline \multirow[t]{2}{*}{ Outdoor activities before dawn and after dusk } & Yes & $55(87)$ & $33(52)$ & $6.3(2.6-15.2) *$ & $8.3(1.1-62.7) * *$ \\
\hline & No & $8(13)$ & $30(48)$ & & \\
\hline \multirow[t]{2}{*}{ Evening meals } & Outdoors & $50(79)$ & $29(46)$ & $4.5(2.1-9.9) *$ & $2.4(0.3-18.3)$ \\
\hline & Indoors & $13(21)$ & $34(54)$ & & \\
\hline \multirow[t]{2}{*}{ House Sprayed (IRS) } & Yes & $30(48)$ & $47(75)$ & $0.3(0.2-0.7) *$ & $0.4(0.1-1.2)$ \\
\hline & No & $33(52)$ & $16(25)$ & & \\
\hline \multirow[t]{2}{*}{ Wearing long-sleeved clothes when outdoors } & Yes & $15(24)$ & $21(33)$ & $0.3(0.2-0.7) *$ & $0.2(0.1-0.4) * *$ \\
\hline & No & $48(76)$ & $42(67)$ & & \\
\hline \multirow[t]{2}{*}{ Ever received health education on malaria } & Yes & $47(75)$ & $59(94)$ & $0.2(0.1-0.6) *$ & $0.1(0.0-0.9) * *$ \\
\hline & No & $16(25)$ & $4(6)$ & & \\
\hline
\end{tabular}

*significant variable in bivariate analysis ${ }^{* *}$ significant variable in multivariate analysis $C O R$ crude odds ratio, $a O R$ adjusted odds ratio 
Table 4 Relationship between engaging in outdoor activities and contracting malaria in Mudzi district, Zimbabwe stratified by sex

\begin{tabular}{|c|c|c|c|c|c|c|}
\hline Variable & Category & Outdoor Activity & Cases & Controls & OR (95\% CI) & $P$-Value \\
\hline \multirow[t]{4}{*}{ Sex } & Male & Yes & 22 & 16 & $7.3(1.8-29.5)$ & 0.01 \\
\hline & & No & 3 & 16 & & \\
\hline & Female & Yes & 33 & 17 & $5.4(1.7-17.6)$ & 0.01 \\
\hline & & No & 5 & 14 & & \\
\hline \multirow[t]{2}{*}{ Crude OR } & & & 55 & 33 & $6.3(2.6-15.2)$ & $<0.001$ \\
\hline & & & 8 & 30 & & \\
\hline
\end{tabular}

In the multivariate analysis, a stagnant water body near a house $[\mathrm{aOR}=8.0,95 \% \mathrm{CI}=(2.3-28.6)]$ and engaging in outdoor activities before dawn and after dusk [aOR = $8.3,95 \% \mathrm{CI}=(1.1-62.7)]$ were significant risk factors associated with contracting malaria in villages around Kondo Rural Health Centre adjusted for other factors. Wearing long-sleeved clothes when outdoors at night $[\mathrm{aOR}=0.2,95 \% \mathrm{CI}=(0.1-0.4)]$ was a significant independent protective factor for contracting malaria (Table 3).

\section{Discussion}

In our study, we found that there were a significant number of households that were not sprayed during the previous indoor residual spraying, stagnant water bodies around homesteads due to the rainy season, a lot of homesteads having houses with open eaves and the majority of families having evening meals outdoors and that malaria transmission was mainly due to outdoor activities and inadequate vector control.

The outbreak occurred following the rains that had poured in the area as evidenced by the increase in stagnant water bodies and tall uncut grass around homesteads which were potential mosquito breeding sites. The district had recorded an average of $245 \mathrm{~mm}$ of rainfall in December 2018 which increased to $565 \mathrm{~mm}$ in January 2019 with an average temperature of 28 Degrees Celsius [13]. This occurrence of an outbreak following the rains and characterised by stagnant water bodies near homes and tall grass is similar to findings by Muchena et al. in Shamva district were having long grass near the home had a 2.61 times risk of contracting malaria whilst having a body of water near the home had a 3.41 times risk of contracting malaria and they recommended larval source management to ensure few vector breeding sites [14].

The majority of cases were from Chanetsa and Nyarongo villages which were within $3 \mathrm{~km}$ from Chanetsa Dam and the area was swampy with more stagnant water bodies and this exposed the villagers to mosquito bites considering the majority of families had evening meals outdoors without putting on any protective clothing or use of topical mosquito repellents. This finding is similar to what has been reported by Chiruvu et al. in
Beitbridge where staying $3 \mathrm{~km}$ away from a stagnant water body was 0.3 times protective from contracting malaria [15]. Failure to eliminate mosquito breeding sites by residents in malaria endemic areas has often resulted in malaria outbreaks and some studies in such areas have recommended the need for integrated and coordinated prevention and control measures to complement IRS [16, 17].

Kondo Rural Health Centre Clinic had been utilising village health workers in the diagnosis and treatment of uncomplicated malaria in the community before the outbreak and into the first and second week however as the epidemic progressed this could not be sustained due to a limited supply of RDT kits from the district. This could have been very effective especially in areas such as Vhombodzi and Nyarongo which were more than $10 \mathrm{~km}$ from the clinic given they had no readily available public transport to the health facility. This has been emphasized by Mutsigiri-Murewanhema et al. where they stated the need for VHWs to have malaria commodities at all times if their existence is to make a difference [18]. A longitudinal study in Zambia by Counihan et al. found that appropriately trained and supervised community health workers could use RDTs safely and accurately within the community for up to 12 months post-training [19].

The community had adequate health education on malaria however was not putting the knowledge into practice as characterised by the preventable mosquito breeding sites around houses such as stagnant water pools, tall uncut grass and failure to wear long-sleeved clothes when outdoors at night. This is in contrast to findings by Vundule and Mharakurwa in their study on knowledge, practices, and perceptions about malaria in rural communities were taking preventive measures was significantly related to knowledge of the causes of malaria [20].

A considerable number of community members were engaged in outdoor activities before dawn and after dusk without wearing long-sleeved clothes or using topical mosquito repellents exposing themselves to mosquito bites. This finding is similar to a study by Mugwagwa et al. in Honde valley were they found that engaging in outdoor activities before dawn and after dusk with considerable low utilization of mosquito repellents had a 2.1 times risk of contracting malaria [17]. 
The community demonstrated good health-seeking behaviour despite the majority of them being members of the apostolic sect as they managed to seek health care within 3 days of onset of illness and none reported use of alternative medicine for the treatment of malaria. This is in contrast to findings by Mugwagwa et al. in Honde Valley where the majority of the population were members of the apostolic sect and 38\% of cases reported having used alternative medicine with the frequently mentioned being holy water [17].

The District's EPR team responded swiftly to the outbreak but could not provide adequate RDT kits to village health workers who could have made a difference through active case finding and community treatment of the uncomplicated cases thereby reducing the malaria transmission rate. This is in contrast to findings by Kureya et al. in Chipinge where there were adequate supplies of RDT check kits and blood slides for laboratory investigation of malaria [21].

A limitation in our study was inadequate malaria diagnostic kits to confirm all enrolled controls to be malaria negative hence this misclassified some controls which might have been under the incubation period, therefore, being cases, which could then have underestimated our measures of association. However, despite these limitations' meaningful inferences relevant to the study population could be drawn from our findings. This study strengthens the importance of complementary activities to indoor residual spraying in eliminating malaria morbidity and mortality in endemic areas as the implementation of these were successful in containing this outbreak.

\section{Conclusion}

The majority of the malaria cases were from Makaza, Chanetsa and Nyarongo villages with the risk factors for contracting malaria being having a stagnant water pool near the homestead and engaging in outdoor activities before dawn and after dusk. Wearing long-sleeved clothing when outdoors at night was a significant protective factor against contracting malaria. The health facility had a well-prepared outbreak response plan with adequate medicines and but had a shortage of diagnostic kits. The community was knowledgeable about the causes and risk factors for malaria.

\section{Recommendations}

Following our findings in this study, we recommended immediate social behaviour change communication by the health promotion officer on wearing long-sleeved clothes when outside at night. We also recommended immediate sourcing by the district medical officer and distribution by the district environmental health officer of RDT kits to village health workers. Village health workers were recommended to immediately commence community mobilisation on the destruction of mosquito breeding sites such as stagnant water bodies near homes and cutting tall grass around homesteads. Lastly, training of individuals drawn from the local community in IRS by the district environmental health officer was recommended before the next spraying schedule as utilisation of these cadres would ensure $100 \%$ coverage.

\section{Public health actions}

The PHO was involved in active case finding during the research and assisted two young children with transport to the clinic. The PHO did an environmental assessment to identify mosquito breeding sites in the community and gave feedback to the VHWs to ensure the destruction of these sites. The PHO gave health education and awareness of malaria prevention methods at the end of every interview.

\section{Supplementary Information}

The online version contains supplementary material available at https://doi. org/10.1186/s12889-020-09872-2.

\section{Additional file 1.}

\section{Abbreviations}

ART: Antiretroviral Therapy; AIDS: Acquired Immunodeficiency Syndrome; DEHO: District Environmental Health Officer; DMO: District Medical Officer; EPR: Emergency Preparedness and Report; IDSR: Integrated Disease Surveillance and Report; IRS: Indoor Residual Spraying; LLITNs: Long Lasting Insecticide Treated Nets; MOHCC: Ministry of Health and Child Care; NMCP: National Malaria Control Program; PHO: Public Health Officer; PMD: Provincial Medical Director; RDT: Rapid Diagnostic Test; VHW: Village Health Worker; WHO/AFRO: World Health Organization African Region

\section{Acknowledgements}

We would like to acknowledge the following for their special input and unwavering support to the success of this study: nursing staff at Kondo Rural Health Centre, village health workers for Chanetsa and Nyarongo villages as well as the Mudzi district health executive.

\section{Authors' contributions}

TTM, TKN, SC: conception, design, acquisition, analysis and interpretation of data and drafting the manuscript. TPJ, GS, NTG, TKN, SC: conception, design,

acquisition, analysis and interpretation of data and drafting the manuscript. SC, TPJ, NTG, and TKN: conception, design, data collection, analysis, interpretation and reviewing of the manuscript draft for important intellectual content. NTG, TPJ, GS, and TKN: conception, design, data collection, analysis, interpretation and reviewing of the manuscript draft for important intellectual content. TPJ: conception, design, data collection, analysis, interpretation and reviewing of the manuscript draft for important intellectual content. MT: conception, design, data collection, analysis, interpretation and reviewing of the manuscript draft for important intellectual content. The authors read and approved the final manuscript.

\section{Funding}

The authors funded this project entirely using their pocket funds and savings.

\section{Availability of data and materials}

The datasets generated and analysed during the current study are available from the corresponding author on reasonable request. 


\section{Ethics approval and consent to participate}

Ethical approval for the study was obtained from Mashonaland East Provincial Medical Directorate's Office and the University of Zimbabwe, Department of Community Medicine's Health Studies Office. Written informed consent was obtained from participants before interviews which were done privately. Written parental or guardian consent was obtained on behalf of all participants under 16 years of age as well as the child's verbal assent to participate in the study. Confidentiality was maintained throughout the study by not recording participant names on questionnaires.

\section{Consent for publication}

Not Applicable.

\section{Competing interests}

The authors declare no competing interests whether financial and nonfinancial.

\section{Author details}

${ }^{1}$ Department of Community Medicine, University of Zimbabwe, Harare, Zimbabwe. ${ }^{2}$ Ministry of Health and Child Care, Family Health Department Nutrition, Harare, Zimbabwe.

Received: 13 April 2020 Accepted: 10 November 2020

Published online: 19 November 2020

\section{References}

1. World Health Organization. The state of health in the WHO African Region: an analysis of the status of health, health services and health systems in the context of the Sustainable Development Goals. 2018. https://www.afro.who. int/sites/default/files/2018-08/State\%20of\%20health\%20in\%20the\%2 OAfrican\%20Region.pdf. Accessed 24 May 2020.

2. World Health Organization, Global Malaria Programme. Guidelines for malaria vector control. 2019. http://www.ncbi.nlm.nih.gov/books/NBK53811 8/. Accessed 24 May 2020

3. Centers for Disease Control and Prevention. CDC - Parasites - Malaria. Parasites-Malaria. 2019. https://www.cdc.gov/parasites/malaria/index.html. Accessed 5 Mar 2019.

4. World Health Organization. WHO | Malaria. WHO. https://www.who.int/ith/ diseases/malaria/en/. Accessed 5 Mar 2019.

5. World Health Organization, World Health Organization, Global Malaria Programme. Global technical strategy for malaria, 2016-2030. 2015. http:// apps.who.int/iris/bitstream/10665/176712/1/9789241564991_eng.pdf?ua=1. Accessed 5 Mar 2019.

6. World Health Organization. Fact sheet about Malaria. https://www.who.int/ news-room/fact-sheets/detail/malaria. Accessed 5 Mar 2019.

7. World Health Organization. Malaria surveillance, monitoring \& evaluation: a reference manual. 2018. https://apps.who.int/iris/bitstream/handle/10665/2 72284/9789241565578-eng.pdf?ua=1. Accessed 24 May 2020.

8. Debela MB, Kahsay AB, Mokonnon TM. Malaria outbreak and contracting factors in Afar region, Ethiopia, 2016. JPHE. 2018;10:233-40. https://doi.org/ 10.5897/JPHE2018.1000.

9. Zimbabwe - Malaria Operational Plan FY 2018.pdf. https://www.pmi.gov/ docs/default-source/default-document-library/malaria-operational-plans/fy-2 018/fy-2018-zimbabwe-malaria-operational-plan.pdf?sfvrsn=7. Accessed 12 May 2019.

10. Ministry of Health and Child Care, Zimbabwe. Ministry of Health and Child Care - Malaria Control. National Malaria Control Programme. http://www. mohcc.gov.zw/index.php?option=com_content\&view=article\&id $=174$ : national-malaria-control-programme\&catid=92:national-malaria-controlprogramme\&ltemid=671. Accessed 5 Mar 2019.

11. Zimbabwe National Statistics Agency, United Nations Population Fund. Intercensal demographic survey 2017. 2017. http//wwwwzimstat.co.zw/sites/default/files/img/ publications/Population/ICDS_2017.pdf. Accessed 23 May 2020.

12. Ministry of Health and Child Care, Zimbabwe. 7th Essential Medicines List and Standard Treatment Guidelines for Zimbabwe. 7th ed. Harare: The National Medicine and Therapeutics Policy Advisory Committee, [NMTPAC] Ministry of Health \& Child Care Republic of Zimbabwe; 2015.

13. World Weather Online. Nyamapanda Monthly Climate Averages. WorldWeatherOnline.com. https://www.worldweatheronline.com/ nyamapanda-weather/mashonaland-east/zw.aspx. Accessed 24 May 2020.
14. Muchena G, Gombe N, Takundwa L, Tshimanga M, Bangure D, Masuka N, et al. Factors associated with contracting malaria in Ward 29 of Shamva District, Zimbabwe, 2014. South Afr Med J. 2017;107:420-3. https://doi.org/ 10.7196/SAMJ.2017.v107i5.12204.

15. Chiruvu RT, Kanengoni B, Mungati M, Gombe NT, Bangure D, Tshimanga M, et al. Malaria Outbreak investigation in Chitulipasi, Beitbridge District, Matebeleland South Province, 2015. 1. 2017;2:104-20. https://www.jirdo.org/ index.php/hsn/article/view/961. Accessed 12 May 2019.

16. Workineh B, Mekonnen FA, Sisay M, Gonete KA. Malaria outbreak investigation and contracting factors in Simada District, Northwest Ethiopia: a case-control study. BMC Res Notes. 2019;12:280. https://doi.org/10.1186/ s13104-019-4315-z.

17. Mugwagwa N, Mberikunashe J, Gombe NT, Tshimanga M, Bangure D, Mungati M. Factors associated with malaria infection in Honde valley, Mutasa district, Zimbabwe, 2014: a case control study. BMC Res Notes. 2015; 8:829. https://doi.org/10.1186/s13104-015-1831-3.

18. Mutsigiri-Murewanhema F, Mafaune PT, Shambira G, Juru T, Bangure D, Mungati $\mathrm{M}$, et al. Factors associated with severe malaria among children below ten years in Mutasa and Nyanga districts, Zimbabwe, 2014-2015. Pan Afr Med J. 2017;27. https://doi.org/10.11604/pamj.2017.27.23.10957.

19. Counihan H, Harvey SA, Sekeseke-Chinyama M, Hamainza B, Banda R, Malambo T, et al. Community health workers use malaria rapid diagnostic tests (RDTs) safely and accurately: results of a longitudinal study in Zambia. Am J Trop Med Hyg. 2012;87:57-63. https://doi.org/10.4269/ajtmh.2012.11-0800.

20. Vundule C, Mharakurwa S. Knowledge, practices, and perceptions about malaria in rural communities of Zimbabwe: relevance to malaria control. Bull World Health Organ. 1996;74:55-60 https://www.ncbi.nlm.nih.gov/pmc/ articles/PMC2486838/. Accessed 3 Mar 2019

21. Kureya T, Ndaimani A, Mhlanga M. Malaria outbreak investigation in Chipinge, Zimbabwe: a case-control study. Iran J Parasitol. 2017;12:423-32.

\section{Publisher's Note}

Springer Nature remains neutral with regard to jurisdictional claims in published maps and institutional affiliations.
Ready to submit your research? Choose BMC and benefit from:
- fast, convenient online submission
- thorough peer review by experienced researchers in your field
- rapid publication on acceptance
- support for research data, including large and complex data types
- gold Open Access which fosters wider collaboration and increased citations
- maximum visibility for your research: over $100 \mathrm{M}$ website views per year
At BMC, research is always in progress.
Learn more biomedcentral.com/submissions 